\title{
Lead-free solders for superconducting applications
}

\author{
C Aksoy, T Mousavi, G Brittles, C R M Grovenor, S C Speller
}

\begin{abstract}
In this study, the low temperature properties of some commercial Pb-free solders developed for electronics and aerospace applications were investigated for possible use as superconducting solder materials. Their properties are also compared with in-house $\mathbf{S n}_{35} \mathbf{I n}_{50} \mathrm{Bi}_{15}$ solders being developed to replace the widely used $\mathrm{Pb}$-Bi alloys. Of these materials, the $\mathrm{Sn}_{35} \mathrm{In}_{50} \mathrm{Bi}_{15}$ solder is the best potential candidate for superconducting applications
\end{abstract}

Index Terms - Commercial solders, $\mathrm{Pb}$-free solders, Superconductivity, Tin-based solders,

\section{INTRODUCTION}

$\mathrm{S}_{\mathrm{T}}^{\mathrm{O}}$ OLDERS play a crucial role in the production of electrical and mechanical components in the electronics industry and

Tin-Lead solders have been used for many years because of their combination of low cost, low melting point $\left(183{ }^{\circ} \mathrm{C}\right)$ [1], good wetting, ductility and fatigue-resistant properties. However, environmental and health concerns over lead toxicity has resulted in recent legislation to limit the use of lead-based solders and has encouraged researchers to discover new leadfree solders $[2,5]$. The candidate elements to include in a low melting point lead-free solder include $\mathrm{Ag}, \mathrm{Bi}, \mathrm{Au}, \mathrm{Tl}, \mathrm{Ga}, \mathrm{Hg}$, $\mathrm{Cu}, \mathrm{Zn}, \mathrm{In}, \mathrm{Sn}$ and $\mathrm{Cd}$, although some of these are just as toxic as $\mathrm{Pb}$ and so are unlikely to prove acceptable. Among these, a wide range of tin-based materials have been recognised as important alloys for metal-metal interconnections in the electronics industry [3], even though they are known to easily form an oxide skin when melted which can prevent good wetting. Outside the electronics industry, bismuth-lead solders are widely used in superconducting applications such as the joints between technological superconducting wires and cables in magnets for NMR instruments as well as for high field experiments such as the Large Hadron Collider (LHC) and the upcoming International Thermonuclear Experimental Reactor (ITER) [6,7]. In those large scale applications, the solders play a very important role in the complete superconducting circuit, and both the performance as a solder and as a superconducting material are vital parameters.

This work was supported in part by the Engineering and Physical Sciences Research Council (EPSRC) accounts EP/K503113/1 and EP/K503769/1, and the Tubitak International Post Doctoral Research Fellowship Programme Award \#2219.

C. Aksoy is now with Engineering of Electronics and Communication, Of Technology Faculty, Karadeniz Technical University, 61850, Trabzon, Turkey (e-mail: cananaksoy@ktu.edu.tr )

T. Mousavi, G. D. Brittles C. R. M Grovenor and S. C. Speller are with the Centre for Applied Superconductivity, University of Oxford, OX1 $3 \mathrm{PH}, \mathrm{UK}$
Eutectic $\mathrm{Pb}-\mathrm{Bi}$ is the standard superconducting solder used in industry to join both $\mathrm{NbTi}$ and $\mathrm{Nb}_{3} \mathrm{Sn}$ conductors. These $\mathrm{Pb}-\mathrm{Bi}$ alloys have low melting point $\left(124{ }^{\circ} \mathrm{C}\right.$ for the eutectic $55.5 \%$ Bi composition), relatively high $\mathrm{T}_{\mathrm{c}}(\sim 8.3 \mathrm{~K}$ at about $40 \% \mathrm{Bi}$ ) and high critical field values (e.g. $\mathrm{H}_{\mathrm{C} 2}=1.77 \mathrm{~T}$ at 4.2 $\mathrm{K}$ for $40 \% \mathrm{Bi}$ [8]. However, in the future the same legislation will restrict the use of $\mathrm{Pb}-\mathrm{Bi}$ solder in these applications, and so there is a need to explore replacement solders with suitable superconducting properties.

In our previous studies, we focused on different joint techniques [9] as well as the properties of some $\mathrm{Pb}$-free solders made in our lab [10]. In this study, the superconducting and microstructural properties of commercial $\mathrm{Pb}$-free solders commonly used in the electronics industry were investigated, since these are easily available in large batch sizes. We compare the results to those of an in-house ternary Sn-In-Bi solder. The aim of this work is to see whether widely available $\mathrm{Pb}$-free solders offer any promise as potential superconducting solders, as it would be convenient to move directly from $\mathrm{Pb}-\mathrm{Bi}$ to another commercial product.

\section{EXPERIMENTAL DETAILS}

Commercial Pb-free solders in the Bi-Sn-Ag, Bi-Sn, Sn$\mathrm{Zn}, \mathrm{Ag}$-In and $\mathrm{Sn}$-In systems were purchased from the Indium Corporation of America, and for the in-house solders In, Sn, Bi ingots were bought from Advent Technologies. The commercial solders had nominal compositions in percentages by weight; $\mathrm{Sn}_{42} \mathrm{Bi}_{57} \mathrm{Ag}_{1}, \quad \mathrm{Sn}_{42} \mathrm{Bi}_{58} \quad \mathrm{Sn}_{91} \mathrm{Zn}_{9}, \quad \mathrm{Sn}_{49} \mathrm{In}_{52}$ and $\mathrm{In}_{90} \mathrm{Ag}_{10}$. Our $\mathrm{Sn}_{35} \mathrm{In}_{50} \mathrm{Bi}_{15}$ alloy was fabricated by melting the pure elements in a crucible at $300{ }^{\circ} \mathrm{C}$, and then casting $2 \mathrm{~mm}$ cylindrical samples by extracting melt from the crucible in a cylindrical quartz tube using a pipette system and air cooling to room temperature. Microstructural characterisation was carried out using scanning microscopy (SEM) in a JEOL 5510 or Zeiss Merlin microscope and chemical analysis by energy dispersive X-ray (EDX) analysis using an Oxford Instruments OISDD XMax 150mm detector and Aztec software. The superconducting properties were measured with a Quantum Design Magnetic Properties Measurement System (MPMS). The samples were prepared for MPMS measurement each with the same geometry (diameter $=2 \mathrm{~mm}$, length $=2.5 \mathrm{~mm}$ ) and carefully aligned with the magnetic field in the axial direction.

\section{RESULTS AND DISCUSSION}

The commercial solders were all near-eutectic alloys and the liquidus and solidus temperatures of the $\mathrm{Bi}-\mathrm{Sn}-\mathrm{Ag}, \mathrm{Bi}-\mathrm{Sn}$ and $\mathrm{Sn}-\mathrm{Zn}, \mathrm{Ag}-\mathrm{In}, \mathrm{Sn}-\mathrm{In}$ solders are reported to be $140{ }^{\circ} \mathrm{C}$, $138^{\circ} \mathrm{C}, 199^{\circ} \mathrm{C}, 143^{\circ} \mathrm{C}, 118^{\circ} \mathrm{C}$ respectively [11] Eutectic alloys with a two-phase microstructure are often preferred to make 
superconducting solders as one or both of phases can be chosen to be superconducting [12], and the overall critical field of a eutectic alloy is normally considered to be controlled by the critical field of the majority superconducting phase [13]. EDX phase maps of the 5 commercial alloys are shown in Figure 1. The binary Bi-Sn alloy contains $95 \% \mathrm{Sn}(\mathrm{Bi})$ and $85 \% \mathrm{Bi}(\mathrm{Sn})$; the two terminal solid solutions in this binary system. The ternary Bi-Sn-Ag alloy is very similar, containing roughly the same volume fraction of the two terminal solid solutions, $\mathrm{Bi}(\mathrm{Sn})$ and $\mathrm{Sn}(\mathrm{Bi})$, and a small amount $(<1 \mathrm{vol} \%)$ of the $\mathrm{Sn}_{3} \mathrm{Ag}$ intermetallic. The $\mathrm{SnZn}$ alloy contains a matrix of $96 \% \mathrm{Sn}(\mathrm{Zn})$ and about 3 vol\% of $\mathrm{Zn}(\mathrm{Sn})$ terminal solid solution. The In- $\mathrm{Ag}$ alloy contains a majority phase $30 \% \operatorname{In}(\mathrm{Ag})$ solid solution. The binary eutectic SnIn alloy contains two superconducting phases, the Sn rich $\gamma$ and In-rich $\beta$ phases, and the published transition temperatures for these phases are $4.7 \mathrm{~K}$ and $6.5 \mathrm{~K}$ respectively [14].
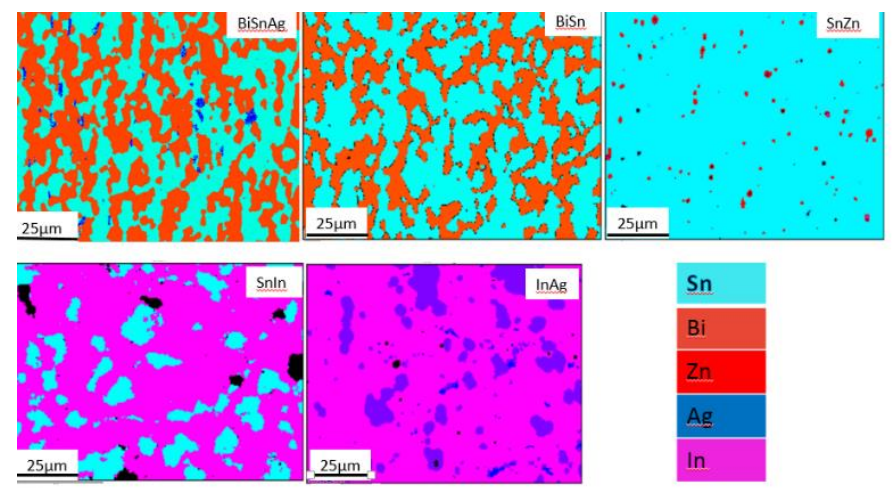

Fig 1. Typical phase maps of the commercial $\mathrm{Pb}$-free solders studied in this work. Each solid solution phase is identified by a characteristic colour as shown in the key on the right hand side.

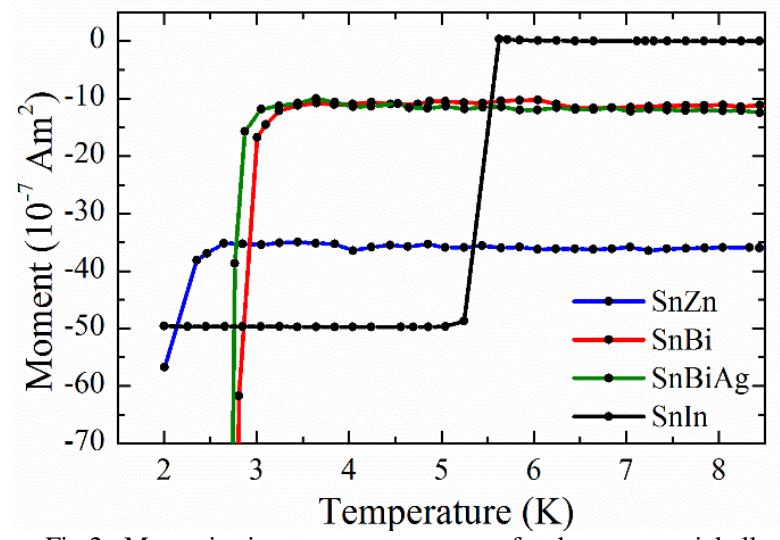

Fig 2. Magnetisation-temperature curves for the commercial alloys showing superconducting transitions. $T_{C}$ values are quoted in the main text

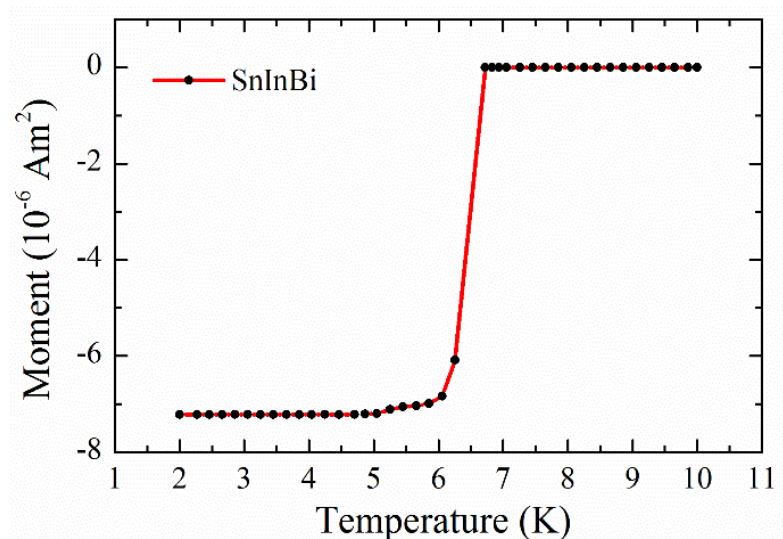

(a)

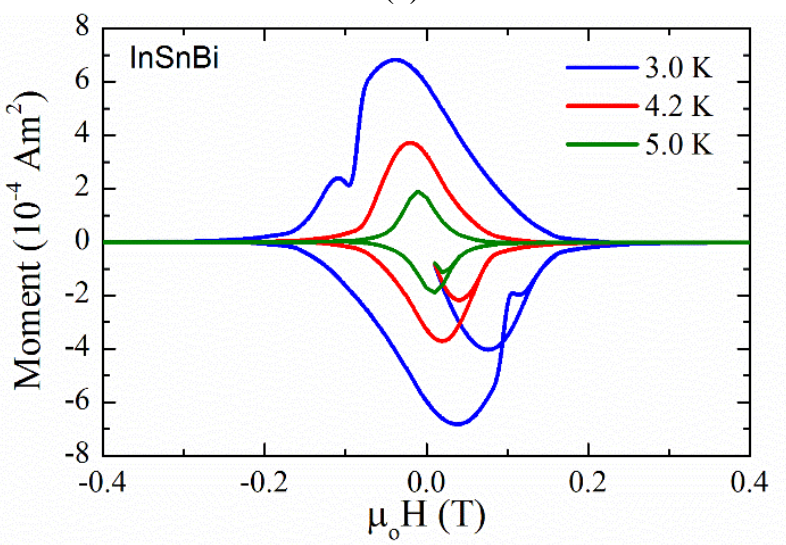

(b)

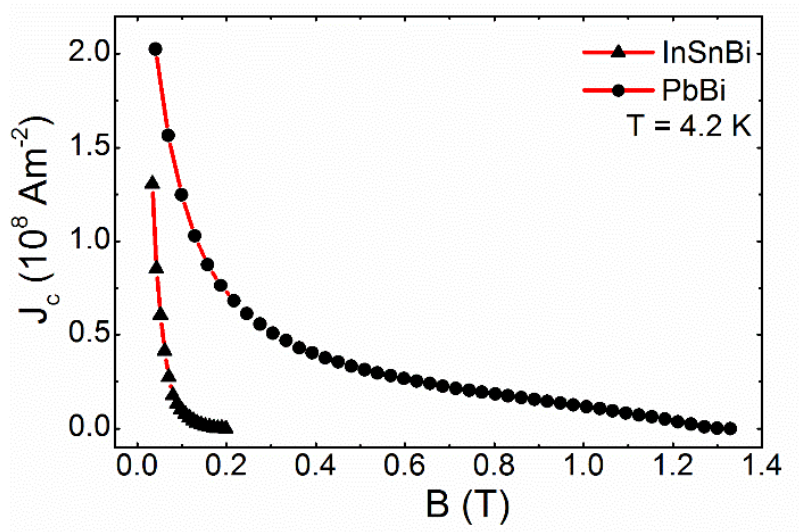

(c)

Fig.4. (a) A magnetisation-temperature curve for the in-house designed Sn- In-Bi solder. (b) Hysteresis loops measured for the Sn-In-Bi solder at $3 \mathrm{~K}, 4.2 \mathrm{~K}$ and $5 \mathrm{~K}$. (c) A comparison between the self-field corrected critical current density $\left(\mathrm{J}_{\mathrm{C}}\right)$ of the $\mathrm{Sn}-\mathrm{In}-\mathrm{Bi}$ and the Pb-Bi solder at $4.2 \mathrm{~K}$ as a function of magnetic field

The magnetisation results from the SQUID experiments are shown in Figure 2, and the superconducting transition onset temperatures of the $\mathrm{Sn}-\mathrm{Bi}-\mathrm{Ag}, \mathrm{Sn}-\mathrm{Bi}, \mathrm{Sn}-\mathrm{Zn}$ solders are $4.0 \mathrm{~K}$, $3.3 \mathrm{~K}$ and $2.6 \mathrm{~K}( \pm 0.2 \mathrm{~K})$ respectively. The $\mathrm{T}_{\mathrm{c}}$ value for the $\mathrm{Sn}-$ $\mathrm{Bi}$ alloy is consistent with literature data for a similar Bi-rich 
alloy of $2.25 \mathrm{~K}$ [12]. In contrast, $\mathrm{Sn}$-rich $\mathrm{Sn}-\mathrm{Bi}$ was found by Levy et al to have a $T_{c}$ value of $4.2 \mathrm{~K}$, higher than the $T_{c}$ of elemental Sn (3.7K) [15]. In addition, the commercial Sn-Zn alloy studied here has a considerably lower Tc than the value reported in the literature for a $\mathrm{Sn}_{85} \mathrm{Zn}_{15}$ alloy [12] of $4.4 \mathrm{~K}$. The binary eutectic $\mathrm{Sn}_{48} \mathrm{In}_{52}$ alloy contains two superconducting phases, Sn- rich $\gamma$ and In-rich $\beta$, contributing to the higher measured value of $5.4 \pm 0.2 \mathrm{~K}$.

The low Tc values of the commercial alloys studied here, even the highest $\mathrm{T}_{\mathrm{c}} \mathrm{Sn}$-In alloy, are a long way below those reported for $\mathrm{Pb}$-In $(6.35 \mathrm{~K})$ [14], and also inferior to the values for the commercial $\mathrm{Pb}$-Bi alloys currently used $(8.4 \mathrm{~K})$. It is clear that most of these commercial solders do not have suitable properties for use in superconducting magnets operating with liquid $\mathrm{He}$ as the cryogen.

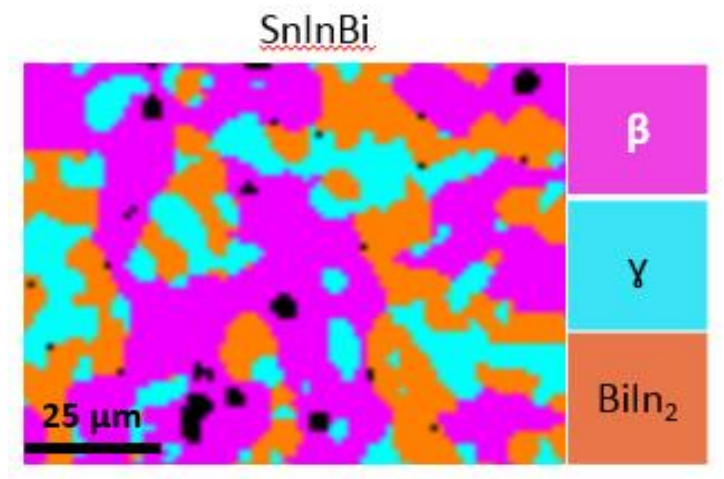

Fig.3. The phase microstructure of the in-house ternary Sn-In-Bi solder

The $\mathrm{Sn}_{35} \mathrm{In}_{50} \mathrm{Bi}_{15}$ solder which we have designed in-house, the liquidus and solidus temperature is $55^{\circ} \mathrm{C}$ [16], to be close to a ternary eutectic composition consists of a majority In-rich $\beta$ phase in which Sn-rich $\gamma$ and $\mathrm{BiIn}_{2}$ are embedded, Figure 3. The superconducting properties of this solder are $\mathrm{T}_{\mathrm{C}}=6.5 \mathrm{~K} \pm 0.2 \mathrm{~K}$, shown in Figure $4 \mathrm{a}, \mathrm{B}_{\mathrm{C} 2}(4.2 \mathrm{~K})=0.14 \mathrm{~T}$ and the $\mathrm{J}_{\mathrm{C}}$ value at 4.2 $\mathrm{K}$ is calculated using Bean's model with appropriate self-field corrections to be $9.5 \times 10^{7} \mathrm{~A} / \mathrm{m}^{2}$ at $0.04 \mathrm{~T}$. These values should be compared to typical values we measure on $\mathrm{PbBi}$ solder (60:40 wt. \%) of $\mathrm{T}_{\mathrm{C}}=8.4 \mathrm{~K}, \mathrm{~B}_{\mathrm{C} 2}(4.2 \mathrm{~K})=1.34 \mathrm{~T}$ and the $\mathrm{J}_{\mathrm{C}}$ value under identical conditions of $2.0 \times 10^{8} \mathrm{~A} / \mathrm{m}^{2}$, are seen Figure 4c.

\section{CONCLUSION}

In conclusion, the commercial solders investigated here are not suitable for use for the manufacture of joints in superconducting magnets. By contrast, solders in the Sn-In-Bi ternary system may be good candidates for further exploration for superconducting applications. The values of the critical parameters we have measured for $\mathrm{Sn}_{35} \mathrm{In}_{50} \mathrm{Bi}_{15}$ are still well below those of the $\mathrm{Pb}$-Bi eutectic solder currently used, but may be improved by exploring a wider range of ternary (and possibly more complex) compositions.

\section{REFERENCES}

[1] Barnak, J. P, Sprecher A. F. and Conrad H.Scripta Metallurgica et Materialia, Vol. 32, No. 6, pp. 879-884,199s, 1995

[2] European Parliament and Council Directive on the Restrictions of the use of certain Hazardous Substances in electrical and electronic equipment Directive 2002/95/EC of 27 January 2003, (OJ No. L37, 13.2.2003, p. 19)

[3] Official Journal of the European Union OJ L4 2014 p61 (Online) Available : (http://eur-lex.europa.eu/legal-content/EN/TXT/? qid=1437982322417\&uri=CELEX:32014L0009)

[4] N.C. Lee Getting ready for lead-free solders Solder. Surf. Mount 9, pp. 65-69, 1997.

[5] Katsuaki Suganuma Advanced in lead -free electronics soldering Current Opinion in Solid State and Materials Science 5 55-64, 2001.

[6] Rossi L Superconductivity: its role, its successes and its setbacks in the Large Hadron Collider of CERN Supercond. Sci. Technol. 23 034001, 2010.

[7] Devred A, Backbier I, Bessette D, Bevillard G, Gardner M, Jewell M, Mitchell N, Pong I and Vostner A Status of ITER conductor development and production IEEE Trans. Appl. Supercond. 22 4804909, 2012.

[8] Evetts J E and Wade J M A 1970 Superconducting properties and the phase diagrams of the $\mathrm{Pb}-\mathrm{Bi}$ and $\mathrm{Pb}-\mathrm{In}$ alloy systems J. Phys. Chem. Solids 31 973-82.

[9] Brittles G D, Mousavi T, Grovenor C R M, Aksoy C and Speller S C. 2015 Persistent current joints between technological superconductors Supercond. Sci. Technol. 28093001

[10] Mousavi, C Aksoy, CRM Grovenor, SC Speller. Microstructure and Superconducting properties of $\mathrm{Sn}-\mathrm{In}, \mathrm{Sn}-\mathrm{In}-\mathrm{Bi}$ alloys as $\mathrm{Pb}$ - free superconducting solders, Supercond. Sci. Technol. 29 (2016) 015012

[11] Research solder kit information (2015) [online] Available: www.indium.com/technical-documents/product-datasheets/download.php?docid $=136-2015$.

[12] G D Brittles et al Persistent current joints between technological superconductors, 2015 Supercond. Sci. Technol. 28093001

[13] Livingston, J.D., superconducting properties of eutectics. Communications: p. 2408-2410, 1966.

[14] W. H. Warren Jr. and W. G. Bader Superconductivity Measurements in Solders Commonly Used for Low Temperature Research. Review of Scientific Instruments 40, 180, 1969.

[15] Levy S A Effect of structure on the superconducting properties of eutectic alloys J. Appl. Phys. 37 3659. 1966.

[16] Mousavi T, Aksoy C, Grovenor, Speller S. IEEE Transactions on Applied Superconductivity, 2016. DOI 10.1109/TASC.2016.2514843 